\title{
¿Qué significa participar? Reflexiones sobre la construcción de las imágenes de la participación*
}

\author{
Jone Martínez-Palacios \\ Universidad del País Vasco / Euskal Herriko Unibertsitatea. \\ Parte Hartuz: estudios sobre democracia participativa \\ jone.martinez@ehu.eus
}

Recepción: 06-05-2016

Aceptación: 09-05-2017

Publicación: 25-04-2018

\section{Resumen}

La participación constituye el corazón de toda teoría y práctica democrática. Reflexiones clásicas y contemporáneas de la democracia se hacen eco del imperativo participativo. Sin embargo, existen distintas nociones de lo que significa participar que dependen, entre otros elementos, del posicionamiento teórico en el campo académico del agente que enuncia, y de la posición social del mismo.

Considerando esa diversidad de significados, en este artículo se defiende la idea de que la participación se ve atravesada por distintos ejes de dominación (género, raza, clase social, edad, etcétera); y se explora, desde un punto de vista biográfico, la influencia del género y su relación o su cruce, con otras estructuras como la edad en las formas de concebir la participación. Para ello, se movilizan, de un lado, las biografías de la participación de 42 mujeres y 6 hombres que forman parte de algún dispositivo de innovación democrática de la Comunidad Autónoma del País Vasco. De otro lado, se analizan los datos de 5 grupos de discusión llevados a cabo con 21 de esas 42 mujeres. Se concluye proponiendo tres imágenes orientativas de la participación — concepciones amplia, mixta y restrictiva de la participación - que ayudan a cartografiar la diversidad conceptual en materia de participación y a estudiar las implicaciones teóricas y prácticas del uso de cada una de ellas.

Palabras clave: contrapúblico subalterno feminista; innovaciones democráticas; poder simbólico; teoría feminista; Comunidad Autónoma del País Vasco

* La autora desea agradecer las aportaciones al texto realizadas por el equipo de trabajo de Berrikuntza Demokratiko Feministak y al grupo de investigación Parte Hartuz: estudios sobre democracia participativa, en concreto a Igor Ahedo Gurrutxaga, Alicia Suso Mendaza, Idoia del Hoyo Moreno y Zuriñe Rodríguez Lara. Asimismo, distintos contrastes con Patricia Martínez García y Jean-Nicolas Bach han enriquecido las ideas iniciales que han tomado forma en este texto. Igualmente, las observaciones de las/los dos revisoras/es anónimas/os de Papers han mejorado sustancialmente la primera versión de este trabajo. Gracias a todas ellas por su tiempo y sus críticas constructivas. 
Abstract. What does it mean to participate? Gender influence on the image of participation

Participation is the core of all democratic theory and practice. Both classical and contemporary reflections on democracy echo the participatory imperative. However, there exist different notions of what it means to participate, which depend, among other things, on the enunciating agent's theoretical positioning in the academic field as well as the social position of that agent. Considering this diversity of meanings, this article defends the idea that different domination systems (gender, race, social class, age, etc.) permeate participation and explores, from a biographical point of view, the influence of gender and its relationship with other structures such as age when it comes to ways of understanding participation. To achieve this aim, participatory biographies of 42 women and six men who form part of a democratic innovation apparatus in the Autonomous Region of the Basque Country are used. Furthermore, data from five discussion groups held with 21 of these 42 women are analyzed. The study reveals three images of participation: broad, mixed and restrictive understandings of participation. These images help to map the conceptual diversity on the issue of participation and also to study the theoretical and practical implications of the use of each.

Keywords: feminist subaltern counterpublic; democratic innovations; symbolic power; feminist theory; Basque Country

\section{Sumario}

1. Introducción a los estudios sobre participación

2. ¿Quién define lo que es participación? Herramientas conceptuales para un análisis
3. Metodología

4. Tres imágenes de la participación

5. Conclusiones

Agradecimientos

Referencias bibliográficas

\section{Introducción a los estudios sobre participación}

Las sociedades que transitan hacia formas de organización igualitarias y multiculturales (Fraser, 1997) asisten a una ampliación de la esfera públicaํ. Muestra de ello es la progresiva visibilización de las expresiones de lo que Nancy Fraser denomina "contrapúblicos subalternos» (Fraser, 1990). Estos públicos, a los que la autora norteamericana se refiere como «arenas discursivas paralelas en las que los miembros de grupos sociales subordinados elaboran y difunden contradiscursos con el fin de formular su propia interpretación de sus identidades

1. Empleamos el sentido habermasiano del término esfera pública (Habermas, 1989), revisitado a partir de las críticas de la teoría política feminista (Young, 1990; Fraser, 1990). De modo que la noción designaría un espacio en las sociedades modernas donde la participación política se concretiza por medio de discusiones, tertulias o salones literarios, entre otros. Se trataría del espacio social en el que se materializa la discusión y la participación. 
y necesidades» (1990: 67), estiran la noción de esfera pública por el simple hecho de reclamar su participación en ella ${ }^{2}$.

Una de las consecuencias de tal ampliación es el auge que ha tenido la idea y la práctica de la participación ciudadana a partir de la segunda mitad del siglo XX en lo que se conoce como mundo occidental. Desde ese momento, esta noción toma una centralidad en los campos académico, social, político y militante ${ }^{3}$. Decimos esto porque el área de investigación sobre la democracia participativa y deliberativa cuenta, cada día, con un número mayor de trabajos científicos y redes de conocimiento dedicadas a su estudio (p. ej. Groupement d'Intérêt Scientifique sur la Participation du Public aux Processus Décisionnels et la Démocratie Participative en Francia, el International Observatory on Participatory Democracy, la red Participedia o el Center for Deliberative Democracy de Stanford). Además, las manifestaciones sociales a favor de una mayor participación ciudadana en la toma de decisiones atraviesan el planeta. Prueba de ello son la conocida como Primavera Árabe (Oriente Medio y Norte de África, 2010), el movimiento 15-M (España, 2011), Occupy Wall Street (Estados Unidos, 2011), el Printemps d'Érable (Quebec, 2012), las protestas prodemocracia en Hong Kong (China, 2014), el movimiento Nuit Debout (Francia, 2016), las protestas de la Red Women's March (Estados Unidos, 2017) o las movilizaciones por la defensa de las pensiones públicas y la vida digna (España, 2018). Asimismo, la participación ciudadana constituye una centralidad en los discursos y programas electorales de los partidos políticos que aspiran a consolidar gobiernos democráticos.

En el campo académico, comprobamos la diversidad de formas a través de las que se ha llevado a cabo el análisis del término participación, y el desigual uso de un marco interpretativo explícito de poder que se ha realizado. Habría un primer grupo de trabajos preocupados por la dimensión normativa de la participación. Estos analizan cuáles son los escenarios deseables para poner en marcha procedimientos participativos, recordando, por lo general, que el diseño de estrategias participativas no es solo un asunto técnico, sino que responde a la voluntad de redistribución del poder (Sintomer, 2011; Ibarra, 2008). Existiría un segundo grupo, centrado en el análisis de las consecuen-

2. Fraser se refiere a esos públicos de los márgenes hasta finales de la década de 1990 como «contrapúblicos subalternos» (Fraser, 1996). Más adelante hablará más ampliamente de «arenas discursivas (...) entre una variedad de diferentes públicos» (Fraser, 2008; 2013).

3. Empleamos el sentido del término campo en su sentido bourdiano. En términos generales, «se puede decir que en todo campo hay siempre una lucha por el monopolio de un tipo determinado de bienes raros, de capital. La lucha por este monopolio tiende a organizarse alrededor de la oposición entre los defensores del monopolio y esos que quieren entrar en el mercado sin el capital adecuado» (Bourdieu, 2013: 21). De modo que los campos son espacios de lucha en los que se busca la acumulación de lo que el autor denomina «bienes raros», que no son otra cosa que las distintas formas de capital (social, económico, cultural) que están en disputa. En lo que respecta a campo militante, rescatamos la propuesta de Ponpeau y Mantoni (2004) para designar el lugar en el que, sin realizar un ejercicio directo del poder político, se interviene en él (a través de movimientos sociales u organizaciones no gubernamentales). 
cias de la participación, entre las que destacan: la capacidad empoderante y el aumento del capital social. En estos trabajos, la redistribución del poder se presenta como una consecuencia deseable (Putnam et al., 1993; Abelson et al., 2006). Habría un tercer grupo ocupado en el diseño técnico y la implementación de los dispositivos de participación. Las aportaciones de Fishkin sobre las encuestas deliberativas (2009) o las de Dienel sobre los núcleos de intervención participativa son un ejemplo de ello (2000). En este caso, prima una reflexión sobre los aspectos técnicos de los procesos, y queda desdibujada su relación con el objetivo central de la democracia participativa: poner el poder de decidir en manos de la ciudadanía. En cuarto lugar, distinguimos un conjunto de trabajos que estudian la participación sectorial, y por tanto priorizan una entrada temática al análisis de las relaciones de poder. Situamos aquí los trabajos relativos a la sostenibilidad y la participación (Barcena, 2004), género y participación (Pateman, 2011; Verge, 2015) o interseccionalidad y participación (Berger, 2009; Collins, 2017).

El trabajo que presentamos en este artículo se sitúa en el ámbito de los estudios feministas sobre la participación. De modo que las aportaciones de los estudios de críticos que reivindican una reflexión sobre el poder son la referencia principal de la interpretación que se presenta aquí (Collins, 1990; Young, 2000; Fraser 1997).

Dentro de los estudios sobre la participación de las mujeres y otros grupos sociales tradicionalmente excluidos de los procesos de toma de decisión, además de los trabajos centrados en analizar la participación de las mujeres en las estructuras de representación (Caul, 1999; Viterna et al., 2008), y de aquellos que se basan en el campo militante fundamentalmente interesados en el análisis de los movimientos sociales a partir de una mirada feminista (Falquet, 2005; Alfama, 2009; Biglia, 2013); es posible identificar una entrada al estudio de la participación de las mujeres y otros agentes subalternos a partir del análisis de las innovaciones democráticas, es decir, de los procesos de radicalización de los principios democráticos de carácter deliberativo o participativo que se dan en el marco de las democracias representativas ${ }^{4}$ (Mansbridge, 1990).

De un lado, estos trabajos ponen de manifiesto las consecuencias opresivas de la acumulación desigual de poder simbólico ${ }^{5}$ entre los agentes participantes en un dispositivo de innovación democrática (ID). Entre otras, Jane Mansbridge ofrecía un ejemplo de cómo actúa ese poder simbólico en los espacios de participación al destacar que en la participación que se daba en las asambleas ciudadanas de Selby (Vermont, EE. UU) no existía una obvia élite del poder

4. Concretamente, hacemos nuestra la propuesta del politólogo Graham Smith, para quien las innovaciones democráticas buscarían profundizar, al menos, cuatro bienes democráticos: la inclusividad, el control popular, la capacidad de juzgar las decisiones públicas por parte de la ciudadanía y la transparencia en los procesos de toma de decisión (Smith, 2009: 12-13).

5. Entendemos el poder simbólico tal y como lo enuncia Pierre Bourdieu; aquel «poder de constituir la realidad mediante la enunciación, de hacer ver y hacer creer, de confirmar o de transformar la visión del mundo y desde ahí la acción sobre el mundo» (Bourdieu, 1977: 410-411). 
y, sin embargo, el género, la raza y la clase social esgrimían diferencias en la participación de unas y otros haciendo que lo negro, lo pobre o lo femenino significase menos $(1990 ; 1994)$. De otro lado, estos trabajos desvelan que las normas de género atraviesan cualquier producto político diseñado en el seno de un contexto de dominación masculina, lo que delimita, desde el inicio mismo de su producción, el carácter inclusivo del mismo (Martínez-Palacios y Bach, 2016).

A pesar de la variedad de perspectivas, todos estos trabajos coinciden en dos ideas que fundamentan el presente artículo. La primera es que a la participación sí le importa el género, pero también la raza, la clase social, el nivel educativo y la edad, entre otras estructuras sociales (Martínez-Palacios, 2015; 2016); de lo que se deduce que ninguna definición de participación es culturalmente neutra y universal; aunque usemos el mismo concepto no empleamos la misma noción. A este respecto son especialmente relevantes las reflexiones acerca de la interseccionalidad realizadas por algunas feministas negras como Patricia Hill Collins (1990) y Kimbelé Crenshaw (1989). Las autoras invitan a dar un paso más allá en la interpretación de la complejidad con la que se estructuran las relaciones de poder en todos los ámbitos de la vida. Para lo que presentan la interseccionalidad como una herramienta heurística que permite poner nombre a la forma compleja en la que se establecen las relaciones entre la raza, la edad, el género, la clase social y la diversidad funcional (Collins y Bilge, 2016). Coger el guante de las feministas negras permite comprender que el género no actúa solo como eje explicativo de la dominación en la participación, sino que sus consecuencias están interconectadas, cruzadas, con otras estructuras de la dominación definidas por cada contexto, generando una genuina relación de dominación y resistencia en la participación. Es decir, estos trabajos critican el hecho de que se dé por universal una «noción demasiado estrecha de la participación» (Martínez-Palacios, 2013) — a menudo empleada como sinónimo de participación politica - , que invisibilizaría otras formas de tomar parte vinculadas a la comunidad (Collins, 2010) o a la solidaridad social (Komter, 2005), tradicionalmente llevadas a cabo por las mujeres.

La segunda coincidiría en identificar la existencia de un contrapúblico subalterno feminista (CPSF) diverso, tanto en el campo académico como militante, que, habiendo identificado las implicaciones que tiene en términos de opresión para los grupos subalternos el hecho de emplear una noción demasiado restringida de la participación, habría añadido a su agenda de trabajo la necesidad de formular definiciones más amplias del término.

Ambas cuestiones introducen la problemática de este artículo acerca de las implicaciones que tiene, en los proyectos de participación de los agentes sociales, el uso de una noción taxativa de la participación. Para su estudio, se plantean tres hipótesis iniciales. La primera apunta a que quienes constituyen un CPSF dentro de un proceso de innovación democrática, en el sentido dado por Fraser, movilizan una imagen amplia de la participación mediante la que desactivan los posibles obstáculos en la incorporación al espacio público. Con la segunda hipótesis, se considera que quienes no constituyen un CPSF 
movilizan en menor medida una imagen amplia de la participación, y tienden a dar por valido el tándem conceptual de participación = participación política; cuestión que llevaría a invalidar su experiencia participativa anterior $y$, por lo tanto, experimentar su incorporación al espacio público en términos de ruptura. La tercera y última hipótesis, consiste en señalar que los hombres que intervienen en espacios de innovación democrática no tienden a participar de un contrapúblico y emplean una noción más restrictiva de la participación que las mujeres.

Con el fin de trabajar sobre la problemática e hipótesis señaladas, y poder comenzar a responder la pregunta que da título al artículo, en las páginas que siguen analizamos la noción de participación desde una perspectiva biográfica, entendiendo que esta escala microsocial recoge desde la experiencia vivida la construcción cotidiana de los significados de la participación. Para ello, extraemos parte de los datos de una investigación más amplia centrada en la participación de las mujeres en los dispositivos de ID de la Comunidad Autónoma del País Vasco (CAPV) ${ }^{6}$. Por un lado, analizamos la biografía de la participación de 42 mujeres - entre las que hay 16 que forman parte de un CPSF - y 6 hombres que toman parte en alguno de los quince espacios de ID de la CAPV seleccionados para un estudio en profundidad. Por otro lado, estudiamos los datos recogidos en 5 focus group realizados con 21 de esas 42 mujeres. Esto nos permite acercamos, en primer lugar, a la imagen de la participación que proyectan mujeres y hombres en el contexto estudiado y saber más acerca de las estructuras que la condicionan. En segundo lugar, damos cuenta de las implicaciones teóricas y prácticas que tiene la movilización de una u otra concepción de participación.

Para ello, este artículo se estructura en cuatro partes. En la primera, mostramos como un CPSF del campo militante, situado en el término geográfico del Estado español, tiene en su agenda, desde la década de 1990, la resignificación de una noción más amplia de participación. Explicamos que este CPSF ha manifestado su preocupación por las implicaciones de emplear una noción demasiado restrictiva del término, lo que ha llevado a enunciar imágenes más amplias del mismo, al tiempo que a reivindicar un marco interpretativo en el que no se desdibuje la lectura sobre las relaciones de poder que existen en los actos participativos. En un segundo apartado, detallamos los aspectos metodológicos de investigación para acceder a las imágenes (orientativas) de la participación de las que damos cuenta en la tercera parte del artículo. En esta, procedemos a la interpretación de los datos recogidos a partir de tres formas de comprender la participación. Aquí, dedicamos especial atención al perfil del agente que existe detrás de cada una de ellas, y al hacerlo mostramos el interés que tiene avanzar en el uso de marcos interpretativos que incorporen

6. La investigación «Innovaciones Democráticas Feministas» (2015-16) ha sido financiada por Emakunde- Instituto Vasco de la Mujer y ha estado coordinada por la autora de este artículo, quien agradece a Igor Ahedo, Alicia Suso, Zuriñe Rodríguez e Idoia del Hoyo el trabajo realizado. 
la interseccionalidad de la posición social y los procesos de producción de los significados. Por último, el cuarto apartado recoge una respuesta inicial a la pregunta que da título al artículo que permite contrastar las hipótesis de trabajo.

\section{2. ¿Quién define lo que es participación? Herramientas conceptuales para un análisis}

Tras el estallido de Mayo del 68, Carole Pateman escribía que «la popularidad que tiene el concepto de participación provee una buena razón para dedicarle una mayor atención. Además, el reciente aumento de las demandas de una mayor participación eleva una cuestión central en la teoría política: el lugar de la participación en una teoría moderna y sostenible de la democracia» (1970: 1). De esta forma, la pensadora feminista, consciente de que el poder de definir es el poder simbólico que reproduce con "naturalidad" las relaciones de opresión, nos invitaba a preguntarnos: ¿quién define lo que es participación?

En este apartado defendemos que existe una inercia, tanto en las teorías clásicas, cuanto en las críticas modernas de la democracia que no incluyen una reflexión sobre la opresión, a emplear una noción restrictiva de la participación como sinónimo de participación política. Consideramos, además, que esta forma de entender la participación ha sido contestada a partir de una serie de herramientas conceptuales por un CPSF muy diverso, dentro de los campos académico y militante, que ha dado como resultado un estiramiento conceptual del concepto.

Empezando por la teoría clásica de la democracia, en la que encontramos en Schumpeter uno de sus máximos exponentes, se detecta el uso de una noción minimalista de la participación al identificarla, de manera exclusiva, con el método democrático. Desde esta perspectiva, la participación se reduce al acto del voto para la elección de líderes políticos. El método democrático se convierte en el acto participativo central en el que toma parte el agente, por lo que cualquier otra forma de participación adquiere aquí un rol residual. La cuestión es que, tal y como señala Pateman, la concepción schumpeteriana de la democracia constituye un hito en la genealogía de la concepción minimalista de la participación: «La caracterización de Schumpeter del método democrático y del rol de la participación ha sido casi universalmente aceptada en los escritos recientes de la teoría democrática» (1970: 5).

Precisamente, con el fin de estirar más allá del método democrático la noción que nos ocupa en este artículo, surgen, en la segunda mitad del siglo $\mathrm{XX}$, las teorías de la democracia deliberativa y de la democracia participativa. Ambos modelos democráticos tienen como objetivo logar una esfera pública más perfecta en términos de inclusividad. Además, coinciden en señalar la insuficiencia de considerar el método democrático como único espacio de toma de decisiones; algo que Fishkin recogía con ironía al decir que «tendemos a elegir a los candidatos de modo similar a cómo elegimos detergente» (1991: 3). 
Quienes defienden posiciones deliberativas, encuentran en los minipúblicos una herramienta útil para ampliar la noción de participación. Estos públicos artificiales son la materialización concreta de una noción precisa de participar. Encontramos, no obstante, una amalgama de interpretaciones de estos dispositivos que van desde la más restrictiva de Fishkin - la encuesta deliberativa como único minipúblico-, a la más amplia de Fung — quien considera los presupuestos participativos, también, dentro de esta categoría- (Grönlund, 2014: 14). Esta forma de estirar la definición de participación ha sido, sin embargo, contestada desde la teoría política feminista por continuar siendo excluyente y perder de vista un marco narrativo sobre el poder (Pateman, 2011), y la "matriz de dominación" ${ }^{7}$ del contexto en el que se ubica (Collins, 2017). Entre otras autoras, Iris Marion Young señalaba que «el énfasis que los partidarios de la democracia participativa ponen en la mayoría y lo común siguen amenazando con suprimir las diferencias entre los ciudadanos» (1996: 105). Al querer imponer una idea universalizadora de lo que es participar y deliberar, se estaría llevando a cabo un acto de poder y excluyendo a quien no tiene capacidad de significar. Con el fin de evitar que en estos procesos se produzcan situaciones de exclusión, la autora estadounidense invita a pensar en tres herramientas para la deliberación que enmarca en una propuesta de democracia comunicativa: la bienvenida, la retórica y la narración (2000: 53-80). Con la bienvenida, introduce el valor político de reconocer explícitamente al otro, conocer su nombre es un principio para conocer la posición desde la que habla y establecer las buenas condiciones para que el debate, la deliberación y la participación, se desarrollen de forma adecuada. A través de la retórica, ofrece una propuesta a la crítica que realiza sobre los efectos de formular una forma de argumentar restrictiva, que deje fuera el lenguaje figurativo, estético, emotivo empleado por muchas subjetividades y habitus para expresarse ${ }^{8}$. Por último, encuentra en la narración, la exposición vivencial de los hechos, una fórmula a través de la cual dar entrada al razonamiento basado en la vivencia y al relato, en el que se acumula una importante fuente de saber.

7. Con la idea de matriz, la autora invita a reflexionar sobre las estructuras que oprimen en cada contexto. Al proponer esta figura permite recoger la complejidad con la que distintos ejes intersectan en función del contexto de los grupos sociales y los individuos. En otras palabras, con esta herramienta entendemos que «si la raza, la clase y el género constituyen ejes de la opresión que caracteriza la experiencia de vida de las mujeres negras (afroamericanas), es posible pensar que otro tipo de matrices en las que la orientación sexual, la religión o la edad estén presentes expliquen la experiencia de otros grupos» (Collins, 1990: 226).

8. En Esquisse d'une théorie de la pratique (1972: 175), Bourdieu definía los habitus como «sistemas de disposiciones duraderas, estructuras estructuradas predispuestas a funcionar como estructuras estructurantes». Se trata de un producto social incorporado que orienta nuestras disposiciones sociales en función de nuestra posición en el campo. De modo que se trata de los esquemas de comportarse y pensar, de las disposiciones sociales que van asociadas a la posición social que tiene un individuo. Cada campo requiere de unas habilidades, disposiciones, códigos de actuación inscritos en el cuerpo a los que denominamos habitus. En el caso de los procedimientos participativos, podemos hablar de habitus participativo para referirnos a las estructuras incorporadas que requiere el procedimiento (Martínez-Palacios y Bach, 2016). 
Desde esta perspectiva "crítica con la crítica», se ha puesto de manifiesto que los planteamientos participativos en los que está ausente una reflexión explícita sobre la opresión emplean una noción de participación que reproduce la norma social de una «élite (discriminada)» (García, 1994), concebida sobre la necesidad de una mujer doméstica (Komter, 2005), la deslegitimación de un "habitus emocional»" (Gould, 2009; Martínez-Palacios y Bach, 2016; Martínez-Palacios, 2017a) y la despolitización de la práctica dirigida a la comunidad (Collins, 2010; 2017).

De lo hasta ahora dicho, puede deducirse que tanto en la noción de participación de las teorías clásicas de la democracia cuanto en la que se deriva de las críticas deliberativas y participativas subyace la idea de que existen distintos tipos de participación organizados de manera jerárquica. Concretamente, en las concepciones con vocación universalizante de la participación esgrimidas, puede apreciarse la categorización que proponía Nuria Cunill, según la cual existirían la participación ciudadana, la participación social, la participación comunitaria y la participación política $(1991)^{10}$. Las teorías sobre la participación que no son reflexivas con el poder simbólico estarían empleando una noción de participación que solo contempla lo que Cunill denomina participación política y participación ciudadana. Por consiguiente, estarían asignando un papel residual a la participación comunitaria y la participación social, tal y como las define la autora.

Entendemos que es aquí donde reside el riesgo de distinguir una participación formal y visible (política y ciudadana) que se sostiene sobre una informal e invisibilizada (comunitaria y social) y que la antropóloga feminista Jone Miren Hernández denomina «invisible o relacional». Se trata de una participación no reconocida como tal y, sin embargo, a través de esta «las mujeres han podido aprender y demostrar sus habilidades como gestoras sociales implicadas en la mejora de las condiciones de vida de la familia, el vecindario, el pueblo o la comunidad en general. Participación femenina que se concreta en asuntos y

9. Este habitus emocional es definido por Deborah B. Gould como «la actitud emocional parcialmente consciente que los miembros de un grupo han incorporado, es decir, las inclinaciones axiomáticas hacia algunos sentimientos y formas de expresarlos» (2009: 32), y se caracteriza, según nuestra interpretación, por involucrar en el espacio público (en el espacio de ID) las emociones de manera reflexiva, por ejemplo, reivindicando un lugar para hablar sobre los afectos en el marco de la asamblea. Pero también se expresa de manera incorporada, por ejemplo, abrazando, tocando, mirando con cariño o sonriendo a quien se incorpora a una reunión.

10. Según la autora, podríamos encontrar una participación ciudadana en la que se incluyen «todas aquellas experiencias que remitan a la intervención de los individuos en actividades públicas para hacer valer sus intereses sociales» (1991: 170). Además, podría distinguirse una participación política, una participación en las estructuras de las que disponen los sistemas políticos. Encontraríamos un tercer tipo en la "participación social» a la que la autora se refiere como a todo el tipo de participación que surge de la agrupación de individuos en la sociedad para defender sus intereses. Estas agrupaciones no se relacionarían con el Estado tal y como la autora lo entiende, sino que lo harían con otros agentes sociales. Por último, la participación comunitaria haría referencia al tipo de participación orientada al sostenimiento de la comunidad (1991: 44-46). 
tareas vinculadas, muchas veces - aunque no exclusivamente- a las necesidades básicas cotidianas de la familia y la comunidad» (Hernández, 2008: 14).

Es aquí donde consideramos que como respuesta a la voluntad universalizante con la que se emplea la noción de participación en las democracias contemporáneas, se ha constituido un CPSF diverso que actúa en múltiples escalas - desde la internacional, con el ejemplo de la Marcha Internacional de las Mujeres, a la escala más local en la que nos centramos en este artículo-, y en distintos ámbitos de la vida. La función principal de estas arenas discursivas es, siguiendo a Fraser, la de contestar a las pretensiones omniabarcantes de los públicos dominantes a partir de la identificación y la formulación de las vivencias y las necesidades específicas de los grupos que las componen (Fraser, 1990; 2013: 19-54).

Así, en lo que respecta a la noción de participación, este CPSF lleva a cabo su trabajo, de forma multiescalar y respondiendo a diferentes ámbitos. Actúa tanto en el campo académico, a través de intelectuales feministas al desvelar la falsa universalidad de la participación en términos normativos y de cuya muestra nos hemos hecho eco más arriba, cuanto en el campo activista, en el que cada vez se encuentran más evidencias empíricas de que la resignificación del término participación constituye una centralidad de la agenda política. Limitándonos solo a algunos ejemplos de este último campo en el contexto del Estado español, identificamos tres espacios en los que, a partir de la segunda mitad de la década de 1990, un CPSF insiste en la importancia de definir lo que es participar reivindicando un marco interpretativo reflexivo sobre la organización y el ejercicio del poder.

En primer lugar, en el I Congrés de Dones de Barcelona (1997) se creaba un grupo de trabajo sobre participación que manifestaba como sigue la necesidad de resignificar:

Intentamos definir qué entendemos por participación. Es sin duda un concepto complejo. Las acepciones del diccionario son interesantes. La primera es "dar noticia», que es lo mismo que "hacer público», y eso es lo que las mujeres queremos, hacer visibles y que se reconozcan nuestras acciones y decisiones (http://www.bcn.cat/congresdones/cponenc2.htm\#1.1Definir, consulta: 14 de abril de 2015).

En ese mismo congreso, ofrecían una inicial pero amplia definición de participación con un fuerte sentido comunitario, que choca con cualquier concepción restrictiva del término:

Entendemos por participación cualquier actividad, acción y toma de decisión que incida en la construcción colectiva de nuestra sociedad (Congrés, citado en Hernández, 2008: 18).

En segundo lugar, en esa línea, también, se pronunciaban algunas participantes de las IV Jornadas Feministas de Euskal Herria, que en una de sus ponencias apelaban a crear un «nuevo modelo de entender la participación» al 
referirse al rol que tiene que jugar el movimiento feminista en la trasformación social:

Cuando nos referimos a la participación sociopolítica, estamos hablando de un modelo masculino. Tendríamos que crear un nuevo modelo. [...] Cuando las mujeres nos integramos en [el] modelo masculino, normalmente no tenemos nuestra participación garantizada de un modo integral. Siempre cumplimos funciones determinadas, o nuestra capacidad de incidir está muy limitada. [La participación] tiene que ser de calidad, siendo personas con el mismo valor, nuestro puesto tiene que ser valorado igualmente. Para llevar a cabo la dinámica social tenemos que crear nuevos modelos, rompiendo con los vigentes hoy en día (Bilgune Feminista, 2008: 28).

Encontramos un tercer ejemplo en el contrapúblico feminista del movimiento 15-M de Madrid (Feminismos Sol), que con estas palabras recogidas en una de sus publicaciones mostraba sus deseos de no «encorsetarse» y de resignificar ampliando.

No queremos hacer girar el debate en torno a la participación de la Comisión de Feminismos en Sol, sino llevarlo más allá: pensar cómo pensamos, o incluso cómo nos piensa, el o los feminismos en relación al 15-M. Nos surgían algunas dudas: «Pero, ¿y qué es el 15-M?». Anticipamos: no podemos decir qué es, pero sabemos que no queremos cerrarlo en palabras que lo constriñan, limitándolo a la estructura organizativa actual o a determinados lugares y momentos simbólicos. Preferimos entenderlo, por ahora y para la discusión, como una fuerza difusa, compleja y heterogénea, un acontecimiento con el que nuestros cuerpos se han visto sacudidos, descentrados, o también como un proceso cultivado al calor de una política distinta y de la que nos hemos empapado, hecho y sentido parte (Feminismos Sol, 2011: 26).

Detrás de estas propuestas se esconde la idea de que los grupos sociales dominantes que han definido hasta la actualidad lo que significa participar constituyen una élite, y proyectan —no siempre intencionadamente- definiciones que excluyen a los grupos sociales que no comparten su experiencia vital. Por consiguiente, para que la ampliación del espacio público pueda hacerse en los términos más inclusivos posibles, parece necesario atender a esas otras imágenes y formas de entender la participación. Para ello, las ciencias sociales críticas disponen de una serie de herramientas conceptuales que remiten a teorías reflexivas sobre el poder. Llegar a estas imágenes de la participación es una tarea que requiere de un análisis dinámico, atento a los cruces e implicando múltiples escalas que no pretendemos abordar en este artículo. Aquí, avanzamos un primer acercamiento mediante una perspectiva micro, basada en la biografía del agente. Lo hacemos sobre la creencia de que la mejor forma de aproximarse a una actividad social individual y dinámica —en este caso, el proyecto participativo de un agente- es el análisis biográfico centrado en la experiencia vivida, la «ligne d'action militante» (Becker, 1960), trayectoria o biografía de la participación del mismo. 


\section{Metodología}

Las tres imágenes de la participación, así como las implicaciones prácticas que tiene su proyección social, explicadas en el siguiente apartado, son fruto de la interpretación inédita de los datos empíricos obtenidos de dos fuentes de información primarias: 48 biografías de la participación realizadas a 6 hombres y 42 mujeres que toman parte en algún dispositivo de innovación democrática de la CAPV. Y 5 focus group con 21 de esas 42 mujeres. El carácter descriptivoexplicativo de las tres arriba mencionadas, así como la especial atención que se requiere hacia la experiencia vivida de un agente oprimido para responder a la problemática que las recoge, invita al uso de las técnicas cualitativas y dialécticas.

Concretamente, con las biografías se puede acceder a las narraciones vitales de los agentes cuyos relatos son sistemáticamente invisibilizados en la esfera pública, ya que son un tipo de entrevista en profundidad centrado en la experiencia vivida en la temática de participación de un individuo concreto. Estas permiten, además, detenerse en aquellos agentes que forman parte de un contrapúblico para detectar la caracterización de sus discursos. «Lo que se dice en una entrevista normal de historia oral no ha sido nunca antes dicho de esa manera» (González, 2012: 29), y esto posibilita el acceso a discursos no hegemónicos, en este caso, sobre lo que significa participar.

Los grupos de discusión son «un dispositivo diseñado para investigar los lugares comunes que recorren la subjetividad que es así intersubjetividad» (Canales y Peinado, 1994: 296). A pesar de su carácter artificial, constituyen una fuente de información valiosa para acceder al discurso reflexivo del agente, en este caso, sobre la participación. Mediante la discusión guiada entre las personas participantes, los grupos de discusión han permitido acceder a los lugares del discurso sobre la participación en los que los enfoques hegemónicos no se detienen comúnmente.

Los discursos recogidos provienen de personas que en el momento de realizar la investigación (2015- 2016) participaban en algún proceso de innovación democrática de la CAPV. De ellas, el 33\% forman parte de un contrapúblico feminista en alguna de las tres formas que se explican más abajo. Se elige conocer la opinión de quienes participan en un proceso de participación de características similares para indagar en los distintos caminos que dan acceso a un mismo lugar y, por lo tanto, en las distintas imágenes sobre este. Así, tras la elección de una muestra de 15 dispositivos de ID de la CAPV, reconocidos social e institucionalmente por expertos/as técnicos de la participación y representativos de la diversidad participativa del territorio ${ }^{11}, 42$ mujeres y 6

11. Para la detección de la muestra se elaboran 7 entrevistas en profundidad a expertas/os en materia de participación ciudadana, participación de las mujeres y metodologías de la participación. En concreto, los 15 espacios son: Movimiento 15-M Bizkaia, Procedimiento contra la Junta de Accionistas de la Plataforma contra el BBVA, Gaztetxe de Gasteiz, Bilboko Konpartsak, Alarde Mixto de Irun, Proceso Participativo de Astra, Asamblea del Movimiento a favor del Decrecimiento de Bizkaia, Proceso Gure Esku Dago a favor del 
hombres, participantes en alguno estos, fueron seleccionados para la realización de las biografías de la participación. Dicha selección se realizó a través de 5 canales:

1. Autoselección de las participantes a través del contacto directo con las personas que han realizado la función de mediadoras (el 45\%).

2. Selección en base a perfiles concretos a través de contacto con las personas mediadoras (el 35\%).

3. Selección a partir de la técnica de la bola de nieve (10\%).

4. Selección a partir de la observación directa llevada a cabo en el marco de la investigación.

En el 10\% de los casos, las mujeres han sido invitadas a participar tras la realización de observaciones directas en los dispositivos debido al interés que su perfil podría tener en el proceso investigador.

5. En el caso de los 6 hombres, se ha procedido a una selección por perfil, basada en la edad y la diversidad del recorrido participativo hasta llegar al dispositivo.

Para este trabajo, no se ha buscado una representación equilibrada de los discursos entre hombres y mujeres. Por eso la muestra de hombres entrevistados es considerablemente menor que la de las mujeres. Debido al peso que tiene la variable independiente "pertenencia a un contrapúblico feminista», se quieren poner en el centro los discursos de las personas que los configuran, y estas han sido, en su mayoría, mujeres.

En cuanto a sus perfiles, las mujeres participantes tienen entre 18 y 63 años y poseen un alto capital cultural institucionalizado (el $84 \%$ cuenta con un título universitario). En lo que respecta a la situación económica, ninguna de las participantes se define de clase alta o muy baja, y el $58 \%$ lo hace como clase media. El 91\% de las mujeres se encuentra trabajando; si bien es cierto que la gran mayoría (77\%) tiene un contrato de duración determinada, y muchas calificaban de "precarios» los puestos que ocupaban. Estos datos nos permiten ir más allá y reflexionar acerca de qué mujeres no acceden a estos procesos de innovación, y el peso que tiene en el contexto vasco la acumulación de capital cultural institucionalizado a la hora de participar.

Los 6 hombres biografiados tienen entre 27 y 60 años, poseen un capital cultural institucionalizado medio (5 tienen estudios medios), y todos se definen como de clase media. En el momento de realizar la investigación, ningún hombre tomaba parte de alguna forma de contrapúblico feminista.

Para poder estudiar la realidad participativa vasca a través de las tres hipótesis de este estudio, en las que la variable de pertenencia a un contrapúblico

Derecho a Decidir, Consejo de Inmigración de Azkoitia, Asambleas de Barrio de Laudio, Presupuestos Participativos de Oñati, Red de Presupuestos Participativos de Gipuzkoa, Proceso Participativo Empoderando a los Barrios de Donostia-San Sebastián, Proyecto Abusu Sarean, Concejos Abiertos de Álava. 
tiene una presencia central, trabajamos a partir de una propuesta de definición operacional que se desprende de la definición declarativa de contrapúblico de Nancy Fraser. Nuestra definición operacional abarca tres posibilidades ${ }^{12}$. Se mantiene que en un dispositivo de innovación existe un contrapúblico cuando se percibe la presencia de:

1. Una arena constituida por agentes de un colectivo feminista y participantes en tanto que representantes de ese colectivo dentro del espacio de innovación. En este caso, en el seno del colectivo feminista se dispone de espacios y momentos de diálogo — más o menos formalizados_- en los que la persona que participa de la ID expone sus impresiones y pide consejo para trabajar las temáticas que se abordan en él. El CPSF estaría representado, pero sería externo al dispositivo de ID.

2. Una arena constituida por agentes que participan de un grupo nacido específicamente en el espacio de ID, con vocación de contrapúblico. Cuando el dispositivo de ID nace sin vocación feminista, puede chocar con las «necesidades de feminismo» de algunas/os mujeres/hombres que lo componen. Estas/os deciden crear un grupo de mujeres/hombres que trabajan los temas en la forma y el tiempo que ellas/os consideran para luego intervenir en un público más amplio.

3. Una arena conformada por agentes que, aun no siendo miembros permanentes de alguna de las dos formas anteriores, participan de manera regular en sus actividades y colaboran a través de sus intervenciones (mediante charlas, seminarios, reuniones puntuales) en la identificación de las condiciones óptimas para la participación.

Señalamos que 16 de esas 42 mujeres forman parte de un CPSF en alguna de estas tres formas. Son:

1. Mujeres que representan a un colectivo feminista dentro del espacio de innovación democrática.

2. Mujeres que impulsan un grupo feminista dentro del espacio de ID.

3. Mujeres que colaboran de una forma regular en las actividades de los CPSF.

Posteriormente, se han realizado 5 focus group, compuestos por 21 de las 42 mujeres biografiadas ${ }^{13}$. Dos de estos grupos han sido constituidos exclu-

12. Esta definición operativa se ha diseñado en dos fases. Inicialmente, y antes de comenzar el trabajo de campo, se establecieron los criterios básicos de las tres formas en las que los CPSF podrían aparecer a partir de la interpretación de las funciones y características que Fraser confiere a estas arenas. En una segunda parte, y con el trabajo de campo finalizado, la definición operativa se refina a la luz de las situaciones que experimentan las mujeres. Los ajustes realizados a la definición operativa tienen que ver con la concreción de la segunda forma en la que se definía inicialmente y la ampliación de la tercera.

13. Estos grupos han estado sujetos a la disponibilidad de participación de las mujeres. Se trata de 5 grupos con las siguientes composiciones: 2, 6, 6, 4, 3 . 
sivamente por mujeres que forman parte de un CPSF y el resto han sido grupos mixtos. En ellos se ha discutido colectivamente sobre los obstáculos y las estrategias detectadas previamente en las biografías, proceso durante el cual la noción de participación ha tomado una notoria centralidad.

La interpretación de los datos empíricos ha sido organizada, a partir de la noción de participación, dando lugar a la identificación de las tres imágenes sobre lo que significa la participación que se exponen a continuación.

\section{Tres imágenes de la participación}

Existen tres formas posibles de entender la participación que varían en función de la edad, del sexo y del hecho de constituir o no un contrapúblico subalterno feminista. La perspectiva de esta investigación reconocía desde el principio el valor heurístico de la interseccionalidad para explicar la complejidad con la que los agentes sociales experimentan la dominación, la relación con el poder y su perspectiva de la participación. Así, las tres hipótesis indagan en el peso de la estructura de género, y el hecho de pertenecer o no a un contrapúblico en la matriz de dominación que opera en el proceso de producción de significados. Los datos desvelarán que, en el caso de la CAPV, la edad es un elemento explicativo importante a la hora de entender la matriz desde la que se da significado a la participación.

En primer lugar, existe una forma de entender la noción que nos ocupa a la que denominamos, povisionalmente, «concepción amplia de la participación». Esta se caracteriza por identificar cualquier acto transformativo como acto participativo y por conectar con las críticas realizadas por los CPSF de las que nos hemos hecho eco en el apartado anterior. Esta primera imagen se caracteriza por reivindicar un marco interpretativo en el que no se diluya la idea de que definir la participación es una cuestión de poder. En segundo lugar, hemos denominado "concepción mixta de la participación» al grupo de imágenes proyectadas sobre esta que, sin caer en la definición minimalista, tiende a reproducir la división entre participación visible e invisible, dotando de una mayor importancia a la primera sobre la segunda. Aquí, aunque no desaparece la idea de que la definición de participación hegemónica es socialmente construida y responde a una configuración concreta de las relaciones de poder, la distancia personal respecto a esa tesis constructivista es menor y predomina la inercia de incorporar una imagen de la participación basada en dicotomías y jerarquías. En tercer lugar, denominamos «concepción restrictiva de la participación" a todas aquellas imágenes concebidas sobre la ilusión de la existencia de una participación culturalmente neutra y universal de la que se subrayan sus aspectos técnicos, despegados de una interpretación o teoría sobre el poder.

Es importante señalar que esta propuesta no ha de entenderse como un modelo de tres categorías estancas, sino como un continuum dinámico en el que es posible tener posiciones mixtas y viajar de unas a otras. Más aun, se trata de una cartografía simplificada en tres tipos, situada en un momento 
concreto de la historia y la geografía cuyo valor reside en la identificación de tendencias potencialmente excluyentes en la elaboración de políticas de participación ciudadana.

\subsection{La concepción amplia de la participación}

Quienes se ubican en este grupo entienden que participar es todo acto que transforma la sociedad y que definir lo que significa participar es una cuestión de poder. Así, conecta con la idea de participación enunciada por la Xarxa de Dones de Barcelona, introducida en la primera parte del artículo. Según esta concepción, todo acto social que esté proyectado a construir sociedad es participación. Por ello, en esta imagen se considerarían como actividad participativa las organizaciones entre madres y padres destinadas a llevar a las criaturas a la escuela, o la participación en clubs de tiempo libre y recreación, que tradicionalmente han tenido un tratamiento residual en los estudios del comportamiento político mainstream.

Este grupo lo componen, en su totalidad, mujeres que constituyen un CPSF, lo que permite comprobar que quien toma parte de estas arenas discursivas tiende a estirar la noción de participación de tal manera que tengan cabida actividades tradicionalmente invisibilizadas. Es decir, que esta cuestión es un punto de trabajo de las agendas de los contrapúblicos. Además, es posible precisar que, entre quienes constituyen un CPSF, son las mujeres jóvenes (menores de 30 años) quienes mayor tendencia a ampliar la noción de participación han mostrado, incidiendo aquí en la importancia de la edad a la hora de estructurar las definiciones sociales del mundo. Estas comparten, en gran medida, una carrera participativa que comienza en la infancia en los grupos scout o de tiempo libre, y sitúan así a los 7-8 años de edad su primer contacto con la participación. Si bien identifican una diferencia entre esta participación inicial y la que llevan a cabo dentro del espacio de innovación democrática al que pertenecen en la actualidad, todas estas mujeres jóvenes dicen ser deudoras de los aprendizajes participativos de esos primeros grupos, tal y como se aprecia en los siguientes testimonios ${ }^{14}$ :

Comienzo a participar en grupos de tiempo libre. Es cierto que en el grupo de tiempo libre participaba de otra manera a cómo lo hago hoy, ahí nos preocupábamos sobre temas como ja ver a qué jugamos! Tenía 7 u 8 años cuando empecé a participar. [...] Y mirándolo desde este momento diría que ahí pongo los cimientos de lo que soy hoy en participación (E, mujer, 29 años, CPSF).

No recuerdo cuándo empecé a participar porque pienso que durante toda mi vida he participado. Desde pequeña me han enseñado a participar, en casa, en la escuela, con las amistades, todo eso era participar. Siempre he

14. Las biografías se han realizado en euskara y castellano. Ofrecemos una traducción de la autora del texto de las biografías realizadas en euskara. Con el fin de identificar el idioma original de la fuente, se añade C (castellano) o E (euskara) en la codificación de cada cita. 
vivido la participación con mucha naturalidad, la verdad (E, mujer, 29 años, CPSF).

En el grupo de mujeres mayores (más de 30 años) que constituyen un CPFS, hay un mayor número de testimonios de mujeres a las que les cuesta verbalizar las experiencias de participación de la infancia como momentos participativos. Además, tal vez por la mayor distancia en el tiempo con estas, tienden a olvidarlas. Una mujer de 46 años a quien biografiamos tardaba en identificar el siguiente episodio de participación al que se refiere en el fragmento que sigue. Durante la conversación, indicaba que su primera experiencia en participación tenía lugar a los 40 años, cuando súbitamente comento:

Ah, bueno, y una cosa de la que, vamos, no me acuerdo frecuentemente pero ahora, según hablamos, pues me ha venido a la mente, y es que cuando era chavalita, muy chavalita, pues tendría 17 o 18 años, me puse a participar en la asociación cultural de mi pueblo. A participar mucho, de hecho; era una asociación formal con su junta directiva y [...] decidieron que yo fuera la presidenta. Quiero decir que me pasé un montón de veranos ocupada en esta asociación cultural, dedicándole un montón de tiempo [...], fíjate que es un episodio de mi vida que tengo totalmente olvidado, pero sí, ese fue el comienzo y seguramente [fue un comienzo] bueno (C, mujer, 46 años, CPSF).

No obstante, dentro de este grupo compuesto por mujeres CPSF, son más los puntos en común que las diferencias que haya podido marcar la edad. Esas similitudes se aprecian en la amplia percepción de lo que es participar, y en, al menos, dos elementos constitutivos de la participación.

El primero, el descubrimiento de su feminismo y el efecto de esta autoconciencia sobre el concepto que nos ocupa. Es en este momento cuando dicen entender la importancia que tiene definir los conceptos que organizan la realidad como una cuestión que afecta al poder. Para muchas, descubrir su feminismo y estirar la noción de participación van de la mano. En uno de los grupos de discusión realizados se recogía la siguiente idea, en la que se aprecia la manera en la que el descubrimiento de "valores feministas» va acompañado de una necesidad de nombrar el mundo de forma más amplia en la que la comunidad toma importancia:

Yo creo que cuando pasas a ser un sujeto feminista pasas a tener unos valores y unas formas de actuar muy concretas. Cuando nos denominamos feministas, detrás hay una forma de ver el mundo, de querer nombrarlo también. Hay una forma de militar, de participar, de ver el amor, las amistades... ¡Todo como lo habíamos definido hasta el momento cambia! (E, grupo de discusión compuesto por mujeres CPSF).

El segundo elemento es la incorporación de un «habitus participativo emocional» coherente con ese estiramiento conceptual, que pasa, entre otras 
cosas, por integrar en la práctica figuras como las de la bienvenida, la acogida o la escucha de la narración, próximas a las que proponía Iris Marion Young (Martínez-Palacios, 2016). Escuchar al resto, dar la bienvenida y hacer la acogida son, para quien maneja esta imagen de la participación, momentos importantes de la participación, con una fuerte dimensión del poder:

En ese momento empiezo a ser consciente de que participo. Escuchar, decidir entre todas... todo eso. Ahí me doy cuenta de las cosas importantes en la participación como, por ejemplo, el escuchar al resto (E, mujer, 29 años, CPSF).

Siempre propongo, promuevo el cariño o la afectividad [...]. Ver a una persona que está en una presentación o en algún lado, que no sabemos ni quién es y la ves que está sola, pues intentas..., me voy a intentar acercar, jaunque me da un palo de la hostia! Pero bueno, yo qué sé, ha venido aquí, pues se tiene que sentir a gusto, ¿̨no? o sea... No conoce a nadie, yo también he sido nueva en sitios, ¿no?, y siempre agradecerías que alguien se acercase a ti (C, E, mujer, 28 años, CPSF).

De lo anterior se deduce que esta forma de comprender la participación no se caracteriza por organizarla a través de la distinción entre participación social, ciudadana, comunitaria y política (Cunill, 1991); ni tampoco por la jerarquización de una participación dicha pública y visible de otra invisibilizada. Sino por:

1. Reconocer la forma de participar actual del agente como deudora de los primeros pasos en el ámbito.

2. Subrayar la idea de comunidad y poder en el marco interpretativo que se emplea en la definición de participación.

3. Emplear un habitus participativo consecuente con una noción amplia de participación.

Existen, al menos, cuatro implicaciones prácticas en el manejo de una definición amplia de participar. La primera, la consideración como práctica participativa de toda acción de tipo relacional hacia la comunidad, tradicionalmente invisibilizada. La segunda, la toma en consideración como agente participativo de aquellos individuos a los que no se les ha otorgado tal estatus en los análisis sociopolíticos clásicos del área. Abuelas/os, profesoras/es y monitoras/ es pasarían a ser agentes de la participación. La tercera, la consideración como tema público, rompiendo con la dicotomía público versus privado, cuestiones que tradicionalmente no se abordaban fuera de las puertas del hogar $(p \cdot e j$. la vergüenza). La cuarta, la puesta en marcha y la visibilización de un habitus participativo emocional congruente con una interpretación amplia de participación que reivindica el sentido político y participativo de la bienvenida, la narración y la empatía. 


\subsection{Una concepción mixta de la participación}

Existe una segunda forma de ver la participación en la que, si bien no excluyen los primeros pasos de la intervención social del agente como experiencia participativa, estos se organizan en el discurso en un segundo plano, con menor importancia, y "por debajo" de lo que sería la participación política (o en general una participación pública, visible y altamente rutinizada y tecnificada).

En este grupo encontramos a las mujeres que no constituyen un CPSF y a los hombres de menos de 30 años que tampoco lo constituyen. Estas/ os identifican algunos episodios participativos pasados (como participación en grupos de tiempo libre o cultural), pero tienden a desvincularlos de su «yo participativo actual». Es decir, no trazan las líneas conectoras entre uno y otro momento. Además, en esta tendencia a distinguir una y otra forma de participar, hay quienes avanzan una tipología propia a través de la que funcionan y clasifican su propia participación. Delimitan, por ejemplo, una forma de intervenir "reflexiva, consciente» o razonada (la que ponen en marcha en el dispositivo de innovación democrática) de otra que no lo es. Encontramos un caso de este tipo de concepción en el siguiente testimonio. Su protagonista considera como participación el momento de acompańamiento a la comunidad en un grupo de asistencia y ayuda a personas con dependencia a las drogas del que formó parte durante la etapa de su juventud. Sin embargo, es posible apreciar una jerarquía entre esta forma de participar en la que la comunidad toma fuerza, y otra de tipo político y racional que valora más:

Mi participación era simplemente acompañamiento, no era... participación. Teníamos unos turnos, e iba allí en los turnos que me tocaban para acompanar a esas personas, que no estuvieran siempre con sus familiares, sino que estuvieran con otras personas [...], yo era participativa pero no desde una consciencia de voy a formar parte de esta asociación como para mejorarla, transformarla, hacerla evolucionar si hace falta. No, no. Simplemente era..., no sé, como de..., como un peón más, vamos (C, mujer, 36 años, no CPSF, irrupción).

Quienes manejan esta concepción de la participación no hacen desaparecer lo comunitario, y emplean un marco de poder que no presenta la participación como una destreza técnica inalcanzable, sino como un asunto político diferenciado de lo basado en la comunidad, con códigos lingüísticos propios a los que se aspira llegar. Esto hace que exista una ruptura en la biografía de la participación. Esta ruptura entre los momentos iniciales en grupos de tiempo libre o de acompañamiento y su incorporación al espacio en el que participan actualmente (el dispositivo de innovación democrática) es vivida, en numerosas ocasiones, de manera traumática. Las competencias y las disposiciones participativas adquiridas en una primera etapa no son válidas para el modelo participativo desarrollado en estos dispositivos. Y por ello, se generan situaciones 
de ansiedad, como las que manifestaban algunas de las personas biografiadas. Este hombre joven reconoce su participación en la infancia, pero la diferencia claramente de otra a la que aspira llegar, en la que el lugar de la razón y el saber tienen la centralidad:

Pues empecé pues ahí [a participar en el club de tiempo libre] porque iba la cuadrilla. [...] Así fue un poco, que tampoco tenía ninguna inquietud concreta ni nada, estar con mis amigos. [...] Luego, más adelante, quieres participar de cosas [en el dispositivo de innovación democrática], pero sabes que no puedes, porque no tienes discurso. No te enteras, no sabes, vas a una reunión y la mitad de lo que se habla, pues no lo coges. Te lo tienen que estar explicando todo. Entonces, te das cuenta de que tienes que formarte, tienes que leer mucho para saber de qué se habla en una reunión. O cuando lees una nota de prensa o un comunicado de cualquier colectivo, saber lo que estás leyendo. No sé a mí me parecía importante, bueno importante más que nada porque a mí me generaba malestar el no saber (C, hombre, 29 años, no CPSF).

De lo hasta ahora dicho se deduce que el hecho de plantear una definición mixta de la participación tiene, al menos, la implicación práctica de generar una ruptura en la experiencia vital participativa del agente por identificar, legitimar y, en ocasiones, querer alcanzar una forma de participar técnica, que requiere de destrezas lingüísticas y culturales. El proceso de tal ruptura comienza con la diferenciación y posterior jerarquización de distintos tipos de participación, dando pie a un malestar en el agente por no llegar a cumplir con las competencias inscritas en la participación «culturalmente universal». Esto tiene que ver con el hecho de naturalizar dichas competencias y disposiciones sin elaborar, como se hace en la imagen amplia de la participación, una reflexión acerca de la genealogía de la noción que nos ocupa en términos de disposición de poder.

\subsection{La concepción restrictiva de la participación}

Quienes se ubican en esta tercera forma de concebir la participación trazan una línea divisoria entre lo que es y lo que no es participar; y convierten la participación política en sinónimo de participación, a través de una tecnificación o profesionalización de sus funciones y excluyendo de la misma toda actividad informal destinada al cuidado de la comunidad.

Los hombres mayores de 30 años que no constituyen un CPSF han inscrito su discurso en este tipo de conceptualización. Se trata de hombres que entraron directamente a participar en partidos políticos o movimientos sociales a temprana edad (entre 16 y 18 años). A pesar de que relatan momentos de construcción colectiva con otras personas en la escuela o el grupo de amistades de la infancia, en ningún caso los han identificado como espacios de participación, sino como anécdotas de vida.

Es importante subrayar que estos hombres se han mostrado cómodos en los espacios de participación política desde el momento en el que comenza- 
ron a intervenir en ellos y, en ocasiones, los han usado para distinguirse del resto. Este hombre relataba que desde su primer contacto con la política en la infancia supo que era su espacio. En sus palabras se aprecia la reputación que le infiere su «actitud natural» hacia la participación, que en su caso es la participación política.

Yo era el típico listillo de barrio. Me gustaba el rollo de la política. Me gustaba y se me daba bien, lo cual cada vez me gustaba más. Me gustaba mucho tirarme el rollo, hacerme el interesante, todo este tipo cosas que van ligadas a cierta necesidad de rollos valerosos, tampoco sin hacer alardes, pero bueno, sí me gustaba mucho. Creo que desde el primer momento que lo conocí, [ese momento en el] que te encuentras algo cerca y te dices, esto es lo mío (C, hombre, 56 años, no CPSF).

El habitus que requiere la actividad participativa está vinculado a destrezas lingüísticas relacionadas con la fortaleza y la seguridad, que se presentan como naturales y no como el producto lógico de una disposición concreta del campo de poder. Encontramos en el discurso de estos hombres la tendencia a presentar esta participación como universal, y a medir las actividades participativas ajenas en base a esta. El siguiente testimonio de uno de los individuos biografiados muestra esos tics e inercias incorporadas a querer asimilar a todos los agentes en una comprensión particular de participación. Cuando se refiere al hecho de que le "ha tocado" ser el presidente de una asociación, indica que él hubiese preferido que fuese una mujer la presidenta. Dice esto porque considera que ella contaba con las capacidades participativas que él define como necesarias y que, como se aprecia, están estrechamente vinculadas con las actitudes, técnicas, que se valoran en contextos de participación política y concurrencia discursiva:

Además, no todas las mujeres, pero había un tanto de mujeres muy preparadas. No sé cómo decirte. Jefa no, pero que se nota que esta sabe, que quiere, y que tiene las ideas bastante claras [...] Esta [se refiere a la que él deseaba que fuera presidenta] la veo muy preparada, quería que ella fuera presidenta, pero ella dice que prefiere que yo sea presidente y ella secretaria, ipues vale! (C, hombre, 56 años, no CPSF).

Sin embargo, una de las implicaciones de restringir la noción de participación, usarla de forma asimilacionista y presentarla como neutra y universal, consiste en la tendencia a minusvalorar y excluir ciertas formas de intervención vinculadas con la comunidad. A esa minusvaloración se han referido algunas mujeres, que consideran que no se ha tratado con suficiente respecto su implicación en la sociedad a través de los clubs de tiempo libre y grupos comunitarios.

Lo que hacíamos era cuidar y estar con los jóvenes, jugar, ir al monte con ellos, preguntarles la opinión sobre las cosas, bueno esas cosas simples. Y esa forma 
de participar siempre se ha ninguneado, nos decían «vosotras ahí solo jugáis», y yo he tenido un complejo enorme porque lo que yo hacía no era considerado participación (E, mujer, 38 años, CPSF).

De las palabras de esa relatora se desprende que no ha sido capaz hasta la madurez, momento en el que entra en contacto con un CPSF, de identificar la forma de intervenir en la sociedad de la que ella procedía como una forma de participación.

\section{Conclusiones}

Iniciábamos este artículo con tres hipótesis de trabajo para saber más acerca de lo que significa participar. En primer lugar, considerábamos que quienes constituyen un CPSF movilizan una imagen amplia de la participación. Asimismo, apuntábamos que esto permite desprenderse de cualquier sensación de ruptura en el proceso de incorporación al espacio público, desactivando parcialmente los posibles obstáculos que se encuentren en esta entrada. Comprobamos que, en la categorización elaborada, la denominada «noción amplia de la participación» ha sido movilizada por mujeres que constituyen un CPSF. Estas han tendido a interpretar su "yo participativo actual» como deudor de los primeros pasos en participación. Pero sobre todas las cosas, quienes se ubican en este grupo han identificado el poder que tiene el hecho de nombrar lo que es participación, y las implicaciones teóricas y prácticas de ello. Como el contrapúblico feminista en el campo académico, estas mujeres han identificado las formas en las que, en la práctica, se deslegitima un habitus emocional vinculado a la comunidad en el campo de la participación. Para ello, ha sido central la función de acogida y resignificación que atribuye Nancy Fraser a estas arenas discursivas. En estas ha habido un momento para el diálogo acerca del valor político de la bienvenida, o del relato en primera persona para incluir a las personas participantes, dando cuerpo a las figuras teóricas de la democracia comunicativa de Iris Marion Young.

En segundo lugar, proponíamos que quienes no constituyen un CPSF movilizan, en menor medida, una imagen amplia de la participación, y tienden a dar por valido el tándem participación = participación politica. Ello llevaría a invalidar su experiencia participativa anterior $y$, por lo tanto, a experimentar su incorporación en términos de ruptura. El segundo grupo de imágenes de la participación movilizado nos permite corroborar esta hipótesis de trabajo. Quienes emplean una imagen mixta de la participación tienen a medir su experiencia participativa en función de la idea según la cual existe una participación universal a la que debe aspirarse. Toma sentido el uso del concepto mixto porque si bien no niegan que la participación de tipo comunitario sea un asunto político que implica transformación social y ejercicio del poder, se naturaliza la categorización acuñada por Cunill sin realizar un ejercicio reflexivo acerca de la genealogía de la definición imperante de la noción participación política. 
La tercera y última hipótesis consistía en señalar que los hombres que intervienen en espacios de innovación democrática no tienden a participar de un contrapúblico y emplean una noción más restrictiva de la participación que las mujeres. No podemos dar por válida esta hipótesis puesto que hemos podido comprobar que, a pesar de no haber encontrado hombres en ninguna de las formas de contrapúblico, existe una clara diferencia entre hombres menores y mayores de 30 años. En este punto, resaltamos el peso explicativo que tiene la edad en la matriz de dominación a la hora de enunciar, a la que no se le confería demasiada importancia en el planteamiento inicial de esta reflexión, pero que refuerza el interés de aplicar la herramienta de la interseccionalidad al análisis de la participación.

Siguiendo a las intelectuales afroamericanas que forman parte del contrapúblico feminista del campo académico, es necesario atender a la posición social del agente desde un punto de vista reflexivo con la complejidad social, también, en los estudios sobre la participación (Collins, 2017). Al inicio del artículo introducíamos la idea de que a la participación le importa el género, la raza, la edad o la diversidad funcional. Pero no todas estas estructuras tienen el mismo peso en las sociedades, y por ello conviene estudiar «la matriz de la dominación» que existe en cada una de ellas (Collins, 1990, 2017; MartínezPalacios, 2017b). En el caso vasco y en materia de participación, vemos que la matriz no solo está construida por el género, sino también por la edad, el nivel educativo y la clase social. Habría que seguir investigando acerca de la influencia de la raza y la diversidad funcional y las formas en las que interseccionan en las distintas imágenes de la participación.

Por el momento, sabemos que las 48 personas participantes de los espacios de ID vascos comparten ciertas posiciones que muestran que se trata de una élite social más o menos discriminada: acumulación de capital cultural y pertenencia a una clase social media. El nivel educativo y la clase social se imponen como estructuras sociales a la hora de definir qué es participación. Pero la tercera hipótesis avanza el sentido del peso de la edad. Los hombres menores de 30 años comparten visiones enunciadas por mujeres que no constituyen un CPSF, haciendo uso de una imagen de la participación mixta limitadora, en tanto que inscrita en una comprensión técnica del manejo lingüístico, también para ellos. Si bien los hombres mayores de 30 años han empleado una noción restrictiva de participación que tienden a generalizar, los jóvenes tienen discursos más relativos. Este último dato es importante porque podría significar la existencia de un cambio en las nuevas generaciones que nos acerque a posiciones más igualitarias.

Concluimos rescatando la pregunta que da título al artículo: ¿qué significa participar? Esta pregunta, que tanto ha preocupado en el campo académico y en el político-militante, es en realidad una pregunta sobre el poder. Existen multitud de formas de definir esta noción, cuya centralidad es indiscutible en todo modelo democrático. Cada definición y su impacto social constituyen una muestra de la posición social del agente que la enuncia y desvela la matriz de dominación que la condiciona. La concepción minimalista schumpeteria- 
na es el resultado de la adscripción a una genealogía elitista y masculina de la democracia en el campo académico de finales del siglo XXI. Con la estructuración de un contrapúblico feminista en el campo académico, formado por mujeres de diversa raza, posición de clase e identidad sexual, surge la necesidad de ampliar los conceptos para que entren todas las personas en ellos, y se da forma a una completa caja de herramientas conceptual en la que se ponen nombre al habitus emocional, la interseccionalidad, la matriz de la opresión o la participación invisivilizada, entre otras. En el campo político y militante, el diverso contrapúblico feminista ha sentido la misma necesidad de estirar los conceptos y de reflexionar acerca de la dimensión de poder que esconde todo acto de significación. De ahí, y a partir del ejemplo del caso de la CAPV sobre el que se ha reflexionado en este artículo, que, al menos por ahora, podamos responder que significar la participación solo es posible cuando se poseen las condiciones simbólico-materiales paraf hacerlo.

\section{Referencias bibliográficas}

Abelson, Julia et al. (2006). Assessing the Impacts of Public Participation: Concepts, Evidence and Policy Implications. Ottawa: Canadian Policy Reseach Networks. Disponible en web: <http://www.cprn.org/documents/42669_fr.pdf> [Consulta: 21 de abril de 2016].

Alfama, Eva (2009). «Lo riu és vida». Memoria de investigación del Programa de Doctorado en Psicología Social. Barcelona: Universidad Autónoma de Barcelona.

BARCEnA, Iñaki (2004). Democracia ecológica. Madrid: Atrapasueños.

BECKER, Howard (1960). «Notes on the Concept of Commitment». American Journal of Sociology (66), 32-40.

BERGER, Michele (2009). The Intersectional Approach: Transforming the Academy through Race, Class and Gender. EE. UU.: University of Noth Carolina Press.

BigliA, Barbara (2013). «Experiencias fronterizas y efectos de las movilidades sociales y de clase». Papers, 98 (4), 751-772. $<$ https://doi.org/10.5565/rev/papers/v98n4.558>.

Bilgune FeminisTA (2008). «Euskal Herriko IV. Jardunaldi Feministak». IV Jornadas Feministas de Euskal Herria. Celebradas en Portugalete los días 12 y 13 de diciembre.

BouRdieu, Pierre (1972). Esquisse d'une théorie de la pratique. Ginebra: Droz.

- (1977). «Sur le pouvoir symbolique». Annales. Economies, Sociétés, Civilisations, (3), 405-411. <https://doi.org/10.3406/ahess.1977.293828>.

- (2013). «Séminaires sur le concept de champs 1972-1975». Actes de la Recherche en Sciences Sociales, 5 (200), 4-37. $<$ https://doi.org/10.3917/arss.200.0004>.

Canales, Manuel y Peinado, Anselmo (1994). «Grupos de discusión». En Delgado, José Manuel; GuTIÉRREZ, Juan. Métodos y técnicas cualitativas de investigación en Ciencias Sociales. Madrid: Síntesis.

Caul, Mike (1999). «Women's Representation in Parliament: The Role of Political Parties». Party Politics, 5 (1), 79-98. $<$ https://doi.org/10.1177/1354068899005001005>. 
Collins, Patricia Hill (1990). Black Feminist Thought. Knowledge, Consciousness, and The Politics of Empowerment. Londres: Routledge.

- (2010). "The New Politics of Community». American Sociological Review, 75 (1), 7-30. <https://doi.org/10.1177/0003122410363293>.

- (2017). «The Difference That Power Makes: Intersectionality and Participatory Democracy». Investigaciones Feministas, 7 (2): 1-30.

Collins, Patricia Hill y BILGe, Sirma (2016). Intersectionality. Cambridge, UK: Polity Press.

Comisión Feminismos Sol (2013). Dossier de la Comisión de Feminismos de Sol. Madrid: CFS. Disponible en web: <https://n-1.cc/file/download/540220> [Consulta: 6 de mayo de 2017].

CrenshaW, Kimberlé (1989). «Demarginalizing the Intersection of Race and Sex: A Black Feminist Critique of Antidiscrimination Doctrine, Feminist Theory and Antiracist Politics». University of Chicago Legal Forum, (149): 139-67. <http:// chicagounbound.uchicago.edu/cgi/viewcontent.cgi?article $=1052 \&$ context $=$ uclf $>$.

Cunill, Nuria (1991). Participación ciudadana, dilemas y perspectivas para la democratización de los Estados latinoamericanos. Caracas: CLAD.

DiENEL, Peter (2000). Repensar la democracia: los núcleos de intervención participativa. Madrid: Ediciones del Serbal.

FALQUET, Jules (2005). "Trois questions aux mouvements sociaux "progresistes" apports de la théorie féministe à l'analyse des mouvements sociaux». Nouvelles Questions Féministes, 24 (3), 18- 35. <https://doi.org/10.3917/nqf.243.0018>.

Fishkin, James (1991). «Democracy and Deliberation: New Directions for Democratic Reform». New Haven: Yale University Press.

- (2009). "When the People Speak: Deliberative Democracy and Public Consultation». Oxford: University Press.

Fraser, Nancy (1990). «Rethinking the Public Sphere: A Contribution to the Critique of Actually Existing Democracy». Social Text, 25/26, 56-80. $<$ https://doi.org/10.2307/466240>.

- (1997). Justice Interruptus: Critical Reflections on the "Postsocialist» Condition. Londres: Routlege.

- (2008). Scales of Justice: Reimagining Political Space in a Globalizing World. Nueva York: Columbia University Press.

- (2013). Fortunes of Feminism. From State-Managed Capitalism to Neoliberal Crisis. Londres: Verso.

García de León, María Antonia (1994). Elites discriminadas. Sobre el poder de las mujeres. Barcelona: Anthropos.

GONZÁLEZ, Miren Llona (2012). Entreverse: teoría y metodología práctica de las fuentes orales. Bilbao: UPV- EHU.

Gould, Deborah (2009). Moving Politics: Emotion and ACT UP's Fight Against AIDS. EE. UU.: University of Chicago Press.

Grönlund, Kimmo et al. (2014). Deliberative Mini-Publics. Involving Citizens in the Democratic Process. UK: ECPR Press.

Habermas, Jurgen (1989). The Structural Tranformation of The Public Sphere: An Inquiry into a Category of Bourgeois Society. Cambridge: MIT Press.

HERNÁNDEZ, Jone Miren (2008). Hacia una cartografía de la participación invisible. Ayudas Francesca Bonnemaison, Diputación de Barcelona. 
IBARRA, Pedro (2008). Relational Democracy. Nevada: Center of Basque Studies.

Komter, Aafke E. (2005). Social Solidarity and the Gift. UK: Cambridge University Press.

Mansbridge, Jane (1990). Beyond Adversary Democracy. Chicago: Chicago University of Chicago.

- (1994). "Feminism and democratic community». Schools of thought in politics. En: OKIN, Susan et al. EE. UU.: Edward Elgar Pub.

MARTÍnEZ-PALACIOS, Jone (2013). "La participation des femmes aux mobilisations environnementales». Nouvelles éditions rationalistes, Raison présente, (186), 27-39.

- (2015). "¿Le importa el sexo a la democracia participativa?». Revista de Estudios Políticos (168), 151-174. <https://doi.org/10.18042/cepc/rep.168.05>.

- (2016). "Equality and Diversity in Democracy: How can We Democratize Inclusively?». Equality, Diversity and Inclusion: An International Journal (35), 350-563. <https://doi.org/10.1108/EDI-04-2016-0030>.

- (Coord.) (2017a). Innovaciones democráticas feministas. Dyckinson: Oñati.

- (2017b). "Exclusión, profundización democrática e interseccionalidad». Revista Investigaciones Feministas, 15 (2): 1-20.

MartíneZ-PALACIOS, Jone y BACH, Jean-Nicolas (2016). «Mujeres y democracia participativa: ¿qué impide los proyectos de participación de las mujeres?». Revista Mexicana de Sociología (78), 497-527. <www.revistas. unam.mx/index.php/rms/article/download/56227/49870>.

Pateman, Carole (1970). Participation and Democratic Theory. Cambridge: Cambridge University Press.

- (2011). Carole Pateman: Democracy, Feminism, Welfare. Nueva York: Taylor and Fracis.

Putnam, Robert, LeOnardi, Robert y NAnetTi, Raffaella (1993). Making Democracy Work. Civic Traditions in Modern Italy. Princeton: Princeton University Press.

Sintomer, Yves (2011). Petite histoire de l'expérimentation démocratique. Tirage au sort et politique d'Athènes à nos jours. París: La Découverte, col. Poches.

SMITH, Graham (2009). Democratic Innovations. Designing Institutions for Citizen Participation. Cambridge: Cambridge University Press.

Verge, Tània (2015). "The Gender Regime of Political Parties: Feedback Effects between Supply and Demand». Politics \& Gender, 11 (4), 754-759. <https://doi.org/10.1017/s1743923x15000483>.

VITERNA, Jocelyn, et al. (2008). «How Development Matters», International Journal Of Comparative Sociology, 49 (6), 459-477. <https://scholar.harvard.edu/files/viterna/files/ijcs2008.pdf>.

XarXa de DONES DE BARCELONA (1998). Transformem la ciutat donant valor a la participació de les dones. Disponible en web: <http://www.bcn.cat/ congresdones/cponenc2.htm\#1Introduccio> [Consulta: 20 de enero de 2015]. 
Young, Iris Marion (1990). Justice and the Politics of Difference. Princeton: Princeton University Press.

- (1996). «Vida política y diferencia de grupo: una crítica del ideal de ciudadanía universal». Perspectivas feministas en teoría política. CASTELLS, Carme. Barcelona: Paidós, 99-127.

- (2000). Inclusion \& Democracy. Nueva York: Oxford University Press. 
